\title{
Human Chorionic Gonadotropin Protects Vascular Endothelial Cells from Oxidative Stress by Apoptosis Inhibition, Cell Survival Signalling Activation and Mitochondrial Function Protection
}

\author{
Daniela Surico $^{a}$ Serena Farruggio ${ }^{b}$ Patrizia Marotta ${ }^{b}$ Giulia Raina ${ }^{b}$ David Mary ${ }^{b, c}$ \\ Nicola Surico ${ }^{a}$ Giovanni Vacca ${ }^{b, c}$ Elena Grossinib,c \\ aDepartment of Obstetrics and Gynaecology, bLaboratory of Physiology, Department of Translational \\ Medicine, University of East Piedmont "A. Avogadro", cExperimental Surgery, Azienda Ospedaliera \\ Universitaria Maggiore della Carità, Novara, Italy
}

\section{Key Words}

Cell death $•$ Mitochondria $\cdot$ Nitric oxide $•$ Peroxidation

\begin{abstract}
Background/Aim: Previous reports have made it hypothetically possible that human chorionic gonadotropin ( $\mathrm{hCG}$ ) could protect against the onset of pregnancy-related pathological conditions by acting as an antioxidant. In the present study we planned to examine the effects of hCG against oxidative stress in human umbilical vein endothelial cells (HUVEC). Methods: HUVEC were subjected to peroxidation by hydrogen peroxide. The modulation of nitric oxide (NO) release by hCG and its effects on cell viability, glutathione (GSH) levels, mitochondrial membrane potential and mitochondrial transition pore opening (MPTP) were examined by specific dyes. Endothelial and inducible NO synthase (eNOS and iNOS), Akt and extracellularsignal-regulated kinases 1/2 (ERK1/2) activation and markers of apoptosis were analyzed by Western Blot. Results: In HUVEC, hCG reduced NO release by modulating eNOS and iNOS. Moreover, hCG protected HUVEC against oxidative stress by preventing GSH reduction and apoptosis, by maintaining Akt and ERK1/2 activation and by keeping mitochondrial function. Conclusion: The present results have for the first time shown protective effects exerted by hCG on vascular endothelial function, which would be achieved by modulation of NO release, antioxidant and antiapoptotic actions and activation of cell survival signalling. These findings could have clinical implications in the management of pregnancy-related disorders.
\end{abstract}




\begin{tabular}{|c|c|c|}
\hline Cellular Physiology & Cell Physiol Biochem 2015;36:2108-2120 & \\
\hline and Biochemistry & $\begin{array}{l}\text { Dor: 10.1159/000430178 } \\
\text { Published online: July 21, } 2015\end{array}$ & $\begin{array}{l}\text { O } 2015 \text { S. Karger AG, Basel } \\
\text { www.karger.com/cpb }\end{array}$ \\
\hline
\end{tabular}

\section{Introduction}

The glycoprotein hormone, human chorionic gonadotropin (hCG), is one of the earliest embryonic proteins produced by the primate embryo and secreted before implantation [1]. In addition to its luteotropic function in pregnancy, previous reports have indicated that hCG could also exert cardiovascular effects. Hence, in anesthetized pigs hCG was recently reported to decrease arterial blood pressure, increase coronary blood flow and myocardial contractility in a dose-dependent way [2]. Similar vascular effects to those found in pigs were shown in uterine and mesenteric resistance arteries of rats [3].

Furthermore, the coronary effects of hCG were related to increased nitric oxide (NO) release. In addition, in porcine coronary artery endothelial cells, hCG was found to stimulate endothelial NO synthase (eNOS)-dependent NO production through the involvement of cAMP/protein kinase A (PKA), extracellular signal-regulated kinases (ERK)1/2, Akt, p38 mitogen-activated protein kinases (MAPK), which were activated as downstream effectors of $\beta_{2}$-adrenoceptor stimulation [2].

Those findings could have clinical implication regarding hemodynamic changes observed during assisted reproductive technologies or preeclampsia [4]. A combination of immunologic, environmental and genetic factors leading to the failure of normal trophoblastic invasion and remodelling of the uterine spiral arteries could be at basis of pre-eclampsia [5]. Pre-eclampsia is hypothesized to be a disorder secondary to decreased placental perfusion which would result in oxidative stress, endothelial activation, and a multi-system maternal disease [5]. Placental ischemia/hypoxia could lead to endothelial abnormalities [6, 7], which in turn would cause hypertension by impairing renal function and increasing total peripheral resistance. Changes in cytokines, reactive oxygen species (ROS) and NO release would be involved in the pathophysiology of pre-eclampsia [8]. Also the release of clustering of apoptotic nuclei into the maternal circulation could be at the basis of endothelial dysfunction observed in pre-eclampsia. Furthermore, widespread apoptosis of the syncytiotrophoblast may also impair trophoblast function leading to the reduction in nutrient transport and a worsening of trophoblast invasion [9].

Although the role of hCG in pre-eclampsia has not been clearly elucidated yet, reported data suggest that it might improve the uterine environment upon implantation by suppressing apoptotic responses in the maternal decidua under oxidative stress [10]. In addition, hCG could play an important role in the peri-implantation period by increasing uterine blood flow [11] and trophoblast invasion [12] as well as through modulation of peroxidation and endothelial function. All the above mechanisms could be at basis of protective effects elicited by hCG against pre-eclampsia.

For this reason in the present study we aimed to examine the effects of hCG against oxidative stress in human umbilical vein endothelial cells (HUVEC). In particular, we have focused on the modulation of NO release and the activation of the different NOS isoforms, the antioxidant system, apoptosis and mitochondria function.

\section{Materials and Methods}

\section{Cell culture}

HUVEC were isolated from voluntary umbilical cord donors who gave informed consent in accordance with the procedures approved by the local institutional ethics committee and according to the Declaration of Helsinki. Cells were cultured as previously described [13]. HUVEC were plated into $0.1 \%$ gelatin-coated flasks in a specific culture medium (EGM-2, endothelial growth media 2) until adhesion with the addition of human epidermal growth factor (hEGF), hydrocortisone, gentamicin-amphotericin B, $\%$ fetal bovine serum (FBS), vascular endothelial growth factor (VEGF), human fibroblastic growth factor (hFGF), recombinant analogue insulin-like growth factor 1 human, ascorbic acid, heparin, $2 \mathrm{mM}$ glutamine and 1\% penicillinstreptomycin and maintained at $37^{\circ} \mathrm{C}$ with $5 \% \mathrm{CO}_{2}$. The cells used for the experiments were obtained from passage 3 to passage 6 . 


\section{Cellular Physiology Cell Physiol Biochem 2015;36:2108-2120 \begin{tabular}{l|l|l}
\hline DOI: 10.1159/000430178 & C 2015 S. Karger AG, Basel
\end{tabular} and Biochemistry Published online: July 21, 2015

For Griess study, $1 \times 10^{4}$ cells were plated in gelatin-coated 24-well plates in EGM-2 complete medium in an incubator until adhesion and then incubated for 4-6 $\mathrm{h}$ in Dulbecco Modified Eagle's Medium (DMEM) supplemented with $2 \mathrm{mM}$ glutamine and $1 \%$ penicillin- streptomycin without FBS and red phenol (starvation medium). The same procedure was followed for mitochondrial membrane potential measurement and mitochondrial permeability transition pore (MPTP) opening, but using $5 \times 10^{4}$ cells. For protein extract studies and glutathione (GSH) quantification, the cells were plated in $0.1 \%$ gelatin-coated flasks in complete medium and, at confluence they were incubated with starvation medium overnight.

\section{NO production}

The NO production was measured in HUVEC's culture supernatants using the Griess method (Promega, Milan, Italy). Cells were treated with $\mathrm{H}_{2} \mathrm{O}_{2}(200 \mu \mathrm{M})$ for $60 \mathrm{~min}$. In addition, the effects of $60 \mathrm{~min}$ hCG (1 $\mathrm{pM}, 100 \mathrm{pM}, 1 \mathrm{nM}, 100 \mathrm{nM}, 1 \mu \mathrm{M}, 100 \mu \mathrm{M}$ ) on NO release in non-peroxidation condition (physiological condition) and during peroxidation were analyzed by giving hCG alone or before $\mathrm{H}_{2} \mathrm{O}_{2}$. Moreover, in some experiments HUVEC were pre-treated with $10 \mathrm{mM} \mathrm{L-NG-nitroarginine} \mathrm{methyl} \mathrm{ester} \mathrm{(L-NAME,} \mathrm{Sigma)} \mathrm{or}$ with the mitochondrial ATP dependent potassium $\left(\right.$ ( $\left.{ }^{2} \mathrm{~K}_{\text {ATP }}\right)$ channels inhibitor, 5 hydroxydecanoate (5HD, $10 \mu \mathrm{M}$, Sigma) before hCG. Those agents and their vehicle were also tested alone. At the end of stimulations, NO production in the sample's supernatants was examined by adding an equal volume of Griess reagent following the manufacturer's instruction. The absorbance at $570 \mathrm{~nm}$ was measured by a spectrometer (BS1000 Spectra Count, San Jose, CA, USA) and the NO production was quantified in respect to nitrate standard curve $[2,14-16]$ and expressed as percentage. The values obtained corresponded to the NO ( $\mu \mathrm{mol})$ produced, after each stimulation, by samples containing $1.5 \mu \mathrm{g}$ of proteins each.

\section{Cell viability}

The cells were treated with $\mathrm{H}_{2} \mathrm{O}_{2}(200 \mu \mathrm{M})$ for 60 min alone or in the presence of hCG $(1 \mathrm{pM}, 1 \mathrm{nM}, 1$ $\mu \mathrm{M}$ and $100 \mu \mathrm{M})$, which was given for $60 \mathrm{~min}$ before $\mathrm{H}_{2} \mathrm{O}_{2}$. In addition, in some samples, hCG (100 $\left.\mu \mathrm{M}\right)$ was administrated after L-NAME $(10 \mathrm{mM})$ or $5 \mathrm{HD}(10 \mu \mathrm{M})$. Control cells were treated with DMEM $0 \%$ FBS and phenol red only. To determine cell viability, the In Vitro Toxicology Assay Kit MTT Based (Life Technologies Italia, Monza; Italy) was used as previously described [16]. This kit is designed to determine cell number spectrophotometrically as a function of mitochondrial dehydrogenases activity in living cells. Briefly, after each treatment, the medium was removed and fresh culture medium without red phenol and FBS and with MTT dye was added in 96-well plates containing the cells and incubated for $2 \mathrm{~h}$ at $37^{\circ} \mathrm{C}$ in an incubator. Thereafter, the medium was removed and an MTT Solubilization Solution in equal volume to the original culture medium was added and mixed in a gyratory shaker until the complete dissolution of formazan crystals. The activity of living cells (cell survival) was determined by measuring the absorbance through a spectrometer (BS1000 Spectra Count, San Jose, CA) and cell viability calculated by comparing results with control cells (100\% viable).

\section{GSH quantification}

For the GSH assay, $1 \mathrm{X} 10^{6}$ cells were treated with $200 \mu \mathrm{M} \mathrm{H}_{2} \mathrm{O}_{2}$ for $60 \mathrm{~min}$ alone or in the presence of hCG ( $1 \mathrm{pM}, 1 \mathrm{nM}, 1 \mu \mathrm{M}, 100 \mu \mathrm{M})$, which was given for 60 min before $\mathrm{H}_{2} \mathrm{O}_{2^{\prime}}$. Cells collected by trypsinization and centrifugation were deproteinized with $5 \% 5$-sulfosalicylic acid solution (wt/vol) and centrifuged at $10,000 \mathrm{~g}$ for $10 \mathrm{~min}$ to remove the precipitates. GSH determination was performed by following the manufacturer's instruction (BioVision Inc., Milpitas, CA) and as previously described [16, 17]. Briefly, HUVEC were homogenized on ice with $100 \mu \mathrm{l}$ of ice cold Glutathione Assay Buffer. Thereafter, $60 \mu \mathrm{l}$ of each homogenate was added to a pre-chilled tube containing perchloric acid (PCA) and vortexed for several seconds to achieve a uniform emulsion. After keeping on ice for $5 \mathrm{~min}$, samples were spun for $2 \mathrm{~min}$ at $13000 \mathrm{G}$ at $4^{\circ} \mathrm{C}$ and the supernatants were collected. Thereafter, $20 \mu \mathrm{l}$ of ice cold $6 \mathrm{~N} \mathrm{KOH}$ was added to 40 $\mu \mathrm{l}$ of PCA preserved samples and after a further 2 min spinning at $13000 \mathrm{G}$ at $4^{\circ} \mathrm{C}, 10 \mu \mathrm{l}$ of the samples were transferred to a 96-well plate where GSH was detected following manufacturer's instructions. Glutathione Standard Curve was prepared using standard GSH following kit instructions. Samples and standards were read by a spectrometer (BS1000 Spectra Count) at an excitation and emission wavelength of $340 \mathrm{~nm}$ and $420 \mathrm{~nm}$. GSH content was expressed as nmol $/ 10^{6}$ cells.

\section{KARGER}




\section{Cellular Physiology Cell Physiol Biochem 2015;36:2108-2120 \begin{tabular}{ll|l} 
DOI: 10.1159/000430178 & $\begin{array}{l}\text { O 2015 S. Karger AG, Basel } \\
\text { www.karger.com/cpb }\end{array}$ \\
\hline
\end{tabular} \\ Surico et al.: Antioxidant Effects of hCG in Endothelial Cells}

Cell lysates

HUVEC were stimulated with hCG for 60 min alone or before $\mathrm{H}_{2} \mathrm{O}_{2}(200 \mu \mathrm{M}, 60 \mathrm{~min})$. At the end of stimulation the cells were washed with PBS 1X supplemented with 1:200 sodium orthovanadate and 1:100 protease inhibitors cocktail (Sigma) and then lysed in an iced-Ripa-buffer (50 mM HEPES, $150 \mathrm{mM} \mathrm{NaCl}$, 0,1\% SDS, 1\% Triton-X100, 1\% sodium deoxycholate, 10\% glycerol, $1.5 \mathrm{mM} \mathrm{MgCl2,} 1 \mathrm{mM}$ EGTA, $1 \mathrm{mM}$ sodium fluoride; Sigma) supplemented with 1:200 sodium orthovanadate and 1:100 protease inhibitors cocktail and phenylmethanesulfonyl fluoride (PMSF; 1:100; Sigma). The extract proteins were quantified through bicinchoninic acid protein (BCA; Pierce, Rockford, IL, USA BCA) and used for electrophoresis and immunoblotting studies.

\section{Western blotting}

Cell lysates ( $30 \mu$ g protein each sample) dissolved in Laemmli buffer $5 \mathrm{X}$, boiled for $5 \mathrm{~min}$, were resolved in 15\% sodium dodecyl sulfate polyacrylamide gel electrophoresis (SDS-PAGE) gels (Bio-Rad Laboratories, Hercules, CA, USA), and after electrophoresis, transferred to polyvinylidene fluoride (PVDF) membranes (Bio-Rad Laboratories), which were incubated overnight at $4{ }^{\circ} \mathrm{C}$ with specific primary antibodies: anti phospho-ERK1/2 (p-ERK1/2, 1:1000; Thr202/Tyr204, Cell Signalling Technologies, Beverly, MA, USA), anti ERK1/2 (1:1000; Cell Signalling Technologies), anti phospho-Akt (p-Akt, 1:1000; Ser473, Cell Signalling Technologies), anti Akt (1:1000; Cell Signalling Technologies), anti phospho-eNOS (p-eNOS, 1:1000; Ser1177, Cell Signalling Technologies), anti eNOS (1:1000; Cell Signalling Technologies), anti iNOS (1:500; Santa Cruz Biotechnology, Inc, CA, USA), anti phospho-Bax (p-Bax, 1:500; Thr167; Assay Biotechnology Company, Sunnyvale, CA), anti Bax (1:500; Sigma), anti Cytochrome C (1:500, Sigma), anti cleaved Caspase-9 (1:500; Vinci-Biochem S.r.L., Vinci, Italy), Caspase-9 (1:500; Sigma), anti cleaved Caspase-3 p11 (1:500; Santa Cruz Biotechnology). The membranes were washed and then incubated with horseradish peroxidasecoupled goat anti rabbit IgG (Sigma), peroxidase-coupled rabbit anti goat IgG and horseradish peroxidasecoupled goat anti mouse IgG (Sigma) for $45 \mathrm{~min}$, and were developed through a nonradioactive method using Western Lightning Chemiluminescence (PerkinElmer Life and Analytical Sciences, Waltham, MA). Phosphorylated protein expression was calculated as a ratio towards specific total protein expression or $\beta$-actin (1:5000; Sigma) detection.

Mitochondrial membrane potential measurement and mitochondrial permeability transition pore (MPTP) opening detection

HUVEC were treated as for cell viability and GSH determination. For mitochondrial membrane measurement the medium of the cells was removed and then incubated with 5,51,6,61-tetrachloro-1,11,3,31 tetraethylbenzimidazolyl carbocyanine iodide (JC-1) $1 \mathrm{X}$ diluted in Assay Buffer $1 \mathrm{X}$ for $15 \mathrm{~min}$ at $37^{\circ} \mathrm{C}$ in an incubator following the manufacturer's instruction (Invitrogen, Life Technologies Europe BV, Monza, Italy), as previously described [16]. The dyes were dissolved in dimethylsulfoxide (Sigma), and the percentage of the organic solvent in the samples never exceeded $1 \% \mathrm{vol} / \mathrm{vol}$. After the incubation, the cells were washed twice with Assay Buffer $1 \mathrm{X}$ and then the suspensions were transferred in triplicates to a black 96-well plate. The red (excitation $550 \mathrm{~nm} /$ emission $600 \mathrm{~nm}$ ) and green (excitation $485 \mathrm{~nm} /$ emission $535 \mathrm{~nm}$ ) fluorescence was measured using a fluorescence spectrometer. To establish the cells undergoing apoptosis, the ratio of red to green fluorescence was determined and expressed as percentage.

For MPTP opening, the sarcolemmal membrane of HUVEC was permeabilized by using $10 \mathrm{mM}$ of digitonin (Sigma) for $60 \mathrm{~s}$ and the cells were loaded with $5 \mu \mathrm{M}$ acetomethoxy derivate of calcein (calcein/ AM, Sigma) for $40 \mathrm{~min}$ at $37^{\circ} \mathrm{C}$. Thereafter, they were washed with Tyrode solution (Sigma) for $10 \mathrm{~min}$ to remove the excess dye. The calcein/AM fluorescence was measured by a fluorescence spectrometer with fluorescence excitation and emission of 488 and $510 \mathrm{~nm}$, respectively.as previously described $[16,17]$.

\section{Statistical analysis}

All data were recorded using the Institution's database. Statistical analysis was performed by using STATVIEW version 5.0.1 for Microsoft Windows (SAS Institute Inc, Cary NC, USA). Data were checked for normality before statistical analysis. One-way ANOVA followed by Bonferroni post hoc tests were used to compare data obtained among various groups. Data represent means of at least five independent experiments for each experimental protocol and are expressed as mean \pm SD. A value of $P<0.05$ was considered statistically significant. 


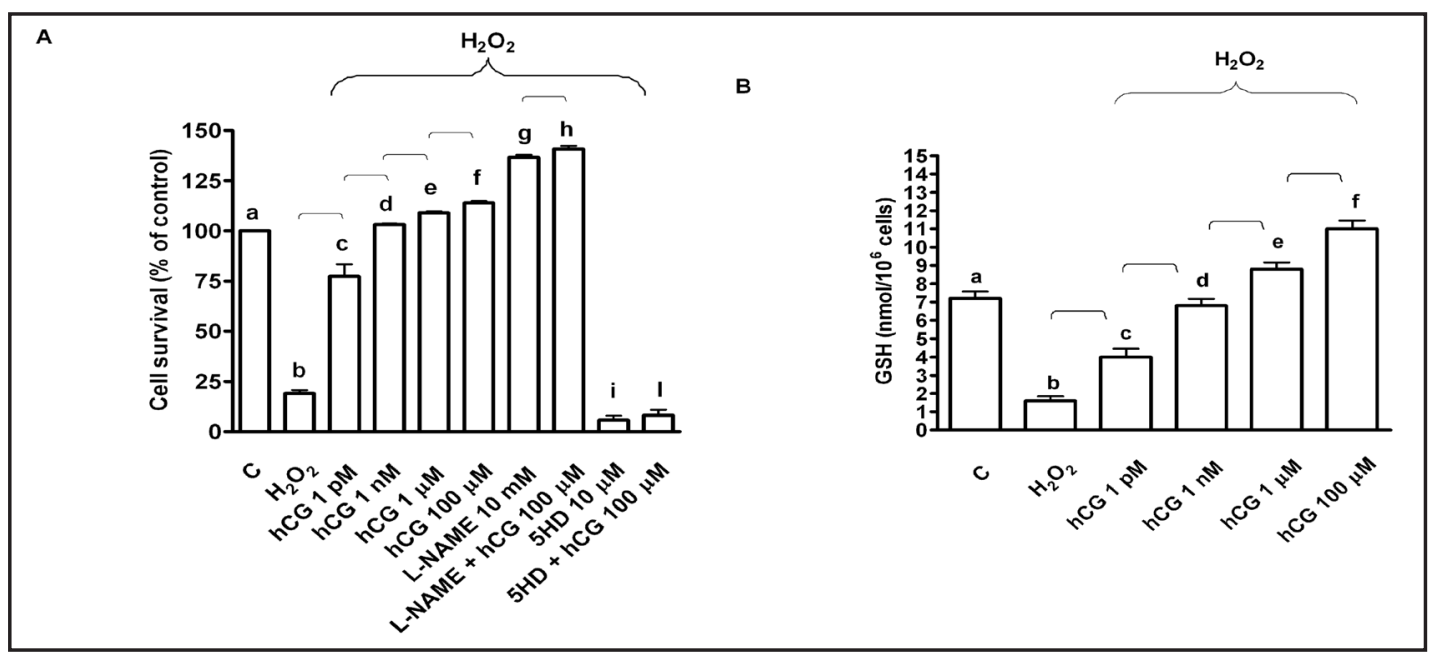

Fig. 1. Effects of hCG on cell survival (A) and glutathione (GSH; B) in HUVEC in peroxidative condition. Cell survival was examined by means of MTT assay, which is designed to determine cell number as a function of mitochondrial dehydrogenases activity in living cells. hCG was administrated at $1 \mathrm{pM}, 1 \mathrm{nM}, 1 \mu \mathrm{m}$ and 100 $\mu \mathrm{m}$ for $60 \mathrm{~min}$ before $60 \mathrm{~min}_{2} \mathrm{O}_{2}(200 \mu \mathrm{M})$. In some experiments HUVEC were pre-treated with L-NAME or 5HD before $100 \mu \mathrm{m}$ hCG. C= control, L-NAME: L-NG-nitroarginine methyl ester; 5HD: 5 hydroxydecanoate. Reported data are mean \pm SD of five independent experiments. In $\mathrm{A}, \mathrm{b}, \mathrm{c}, \mathrm{d}, \mathrm{e}, \mathrm{f}, \mathrm{g}, \mathrm{i} P<0.05 \mathrm{vs}$ a; $\mathrm{d}, \mathrm{e}, \mathrm{f}, \mathrm{g}, \mathrm{i}$ $P<0.05$ vs b; $f<<0.05$ vs c, d; h, $l P<0.05$ vs f. In B, b, c, e, f $P<0.05$ vs a; d, e, f $P<0.05$ vs b; f $P<0.05$ vs c, d. Square bracket indicates significance between the groups $(\mathrm{P}<0.05)$.

Fig. 2. Effects of hCG on NO release (\%) caused by hydrogen peroxide in HUVEC. Griess assay was performed to examine NO release caused by hCG in peroxidative condition. hCG was administrated at $1 \mathrm{pM}$, $100 \mathrm{pM}, 1 \mathrm{nM}, 100 \mathrm{nM}, 1 \mu \mathrm{m}$ and $100 \mu \mathrm{m}$ for $60 \mathrm{~min}$ before 60 min $\mathrm{H}_{2} \mathrm{O}_{2}(200 \mu \mathrm{M})$. In some experiments HUVEC were pre-treated with L-NAME or 5HD before $100 \mu \mathrm{m}$ hCG. C= control, L-NAME: L-NG-nitroarginine methyl ester; 5HD: 5 hydroxydecanoate. b, c, d, e, f, g, h, i, $m P<0.05$ vs a; c, d, e, f, g, h, i, $m P<0.05$ vs b; e, f, g, h $P<0.05$ vs c; f, g, h $P<0.05$ vs d; g, h $P<0.05$ vs e; $h P<0.05$ vs f; l, n $P<0.05$ vs h. Square bracket indicates significance between the groups $(\mathrm{P}<0.05)$.

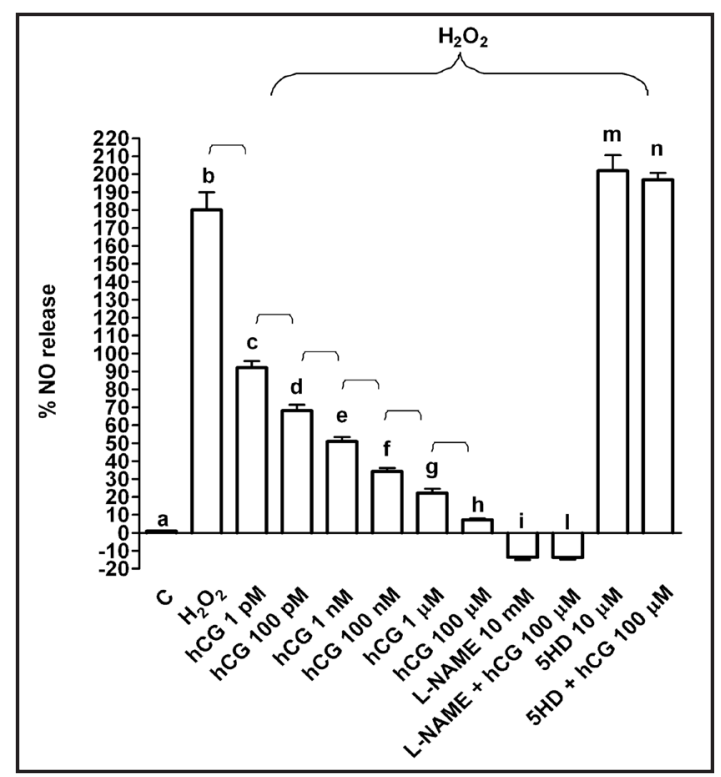

\section{Results}

hCG counteracts peroxidation in HUVEC by improving the antioxidant system, modulating $N O$ release and mitochondria function

In HUVEC pre-treated with $200 \mathrm{\mu M} \mathrm{H}_{2} \mathrm{O}_{2}$, the activity of living cells was reduced to about $19 \%$ from control value of $100 \%$, whereas GSH content decreased to $1.6 \pm 0.8 \mathrm{nmol} / 10^{6} \mathrm{cells}$ from control value of $7.2 \pm 0.8 \mathrm{nmol} / 10^{6}$ cells (Fig. 1). Those effects were accompanied by increased NO release amounting to $180 \%$ of control values (Fig. 2) and by the collapse of mitochondrial membrane potential and activation of MPTP opening (Fig. 3). 


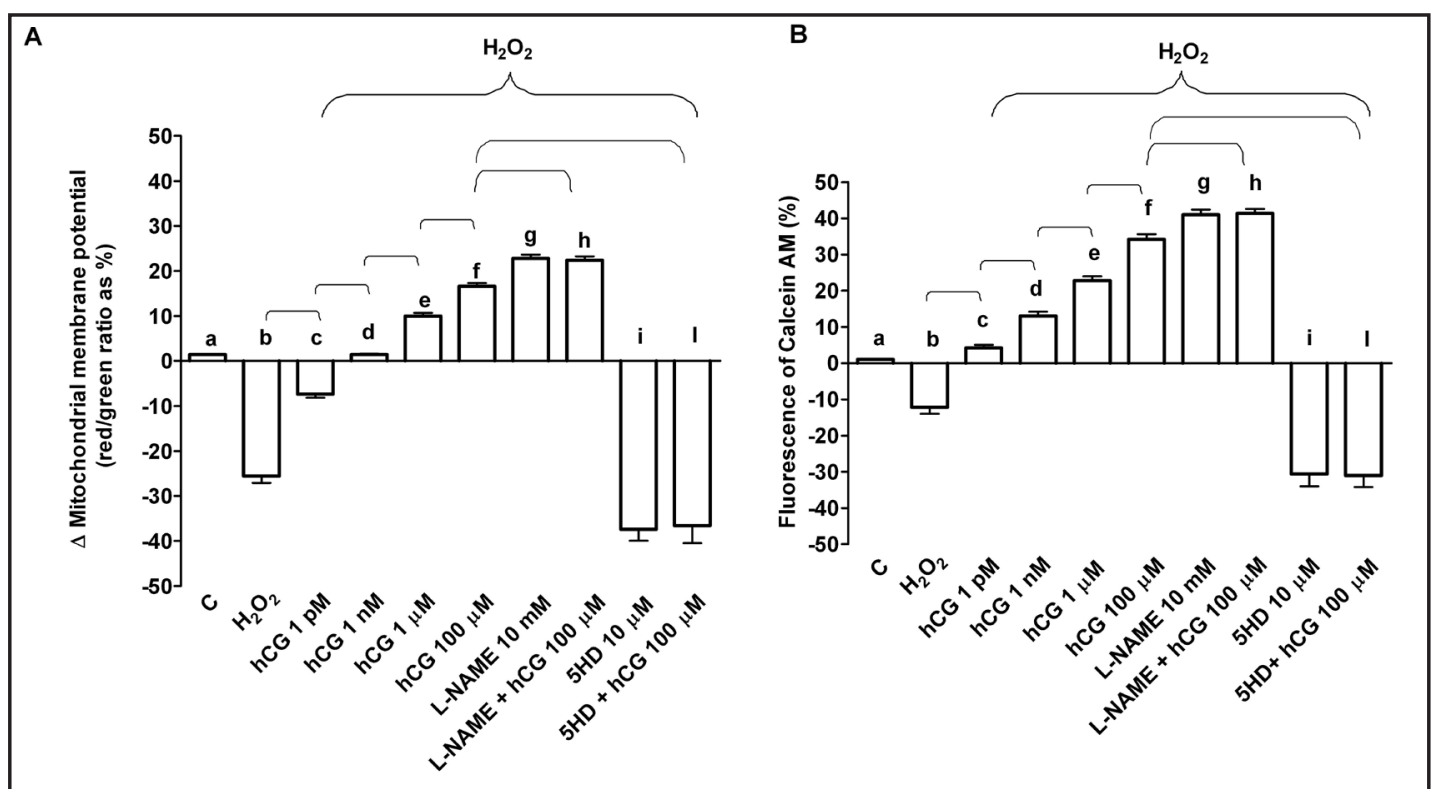

Fig. 3. Protective effects elicited by hCG on mitochondrial membrane potential (A) and transition pore (MPTP) opening (B) in HUVEC that underwent peroxidation. In A, JC-1 assay was performed to examine mitochondrial membrane potential caused by hCG in peroxidative condition. In B, changes of fluorescence of Calcein AM were quantified for examining the MPTP opening caused by hCG in peroxidative condition. hCG was administrated at $1 \mathrm{pM}, 1 \mathrm{nM}, 1 \mu \mathrm{m}$ and $100 \mu \mathrm{m}$ for $60 \mathrm{~min}$ before $60 \mathrm{~min}_{2} \mathrm{O}_{2}(200 \mu \mathrm{M})$. In some experiments HUVEC were pre-treated with L-NAME or 5HD before $100 \mu \mathrm{m}$ hCG. C= control, L-NAME: L-NGnitroarginine methyl ester; 5HD: 5 hydroxydecanoate. In A, b, c, e, f, g, i $P<0.05$ vs a; d, e, f, g, i $P<0.05$ vs b; e, f $P<0.05$ vs c; f $P<0.05$ vs d; h, l $P<0.05$ vs f. In B, b, c, d, e, f, g, i $P<0.05$ vs a; d, e, f, g, i $P<0.05$ vs b; e, f $P<0.05$ vs c; $f<0.05$ vs d; h, l $P<0.05$ vs f. Square bracket indicates significance between the groups $(\mathrm{P}<0.05)$.

In cells that were not treated with $\mathrm{H}_{2} \mathrm{O}_{2}$, hCG increased NO release and eNOS activation in HUVEC in a similar way as that observed in porcine aortic endothelial cells (PAE; Fig. 4A and B) [2]. No significant effects were observed on iNOS (Fig. 4C). Different results were obtained in peroxidative status, where the administration of $60 \mathrm{~min}$ hCG dose-dependently reduced NO release in HUVEC (Fig. 2). These effects were also accompanied by inhibition of eNOS and iNOS activation caused by hydrogen peroxide (Fig. 5).

Moreover, hCG prevented cell death and GSH reduction (Fig. 1) and inhibited the effects of hydrogen peroxide on mitochondrial membrane potential and MPTP opening (Fig. 3). As shown in Fig. 1-3, l-NAME, which abolished the increased NO release by hydrogen peroxide, was able to improve cell survival, mitochondrial membrane potential and MPTP opening. Opposite results were observed in HUVEC pre-treated with 5HD. In these cells, therefore, the survival and mitochondrial function were strongly reduced (Fig. 1 and 3). Moreover, in the presence of those agents, changes in the protective effects of hCG were observed in comparison with what was found in the absence of various inhibitors. The response to hCG of cell survival and mitochondrial function was increased in HUVEC pre-treated with L-NAME in comparison with HUVEC treated with hCG alone (Fig. 1 and 3), whereas after 5HD all protective effects were strongly inhibited and NO release caused by hydrogen peroxide was increased (Fig. 1-3).

hCG inhibits apoptosis and increases cell survival signalling in HUVEC that had undergone peroxidation

As reported in Fig. 6 and 7, in HUVEC pre-treated with hCG, p-Bax, Cytochrome C, p-Caspase 9 and Caspase 3 activation was reduced in comparison with that found in the 
Fig. 4. Effects of hCG on NO release (A) and eNOS (B) and iNOS (C) activation in HUVEC. In A, a dose-response study of the effects of hCG (1 pM, 100 pM, $1 \mathrm{nM}, 100 \mathrm{nM}, 1$ $\mu \mathrm{m}$ and $100 \mu \mathrm{m}$ ) on NO release was performed by Griess assay. In B and C, densitometric analysis and an example of Western Blot taken from 5 different experiments about eNOS and iNOS activation/expression are shown. For densitometric analysis p-eNOS was compared with eNOS, while iNOS was compared with b actin. b, c, d, e $P<0.05$ vs a; $d$, e $P<0.05$ vs b; e $P<0.05$ vs c. Square bracket indicates significance between the groups $(\mathrm{P}<0.05)$.

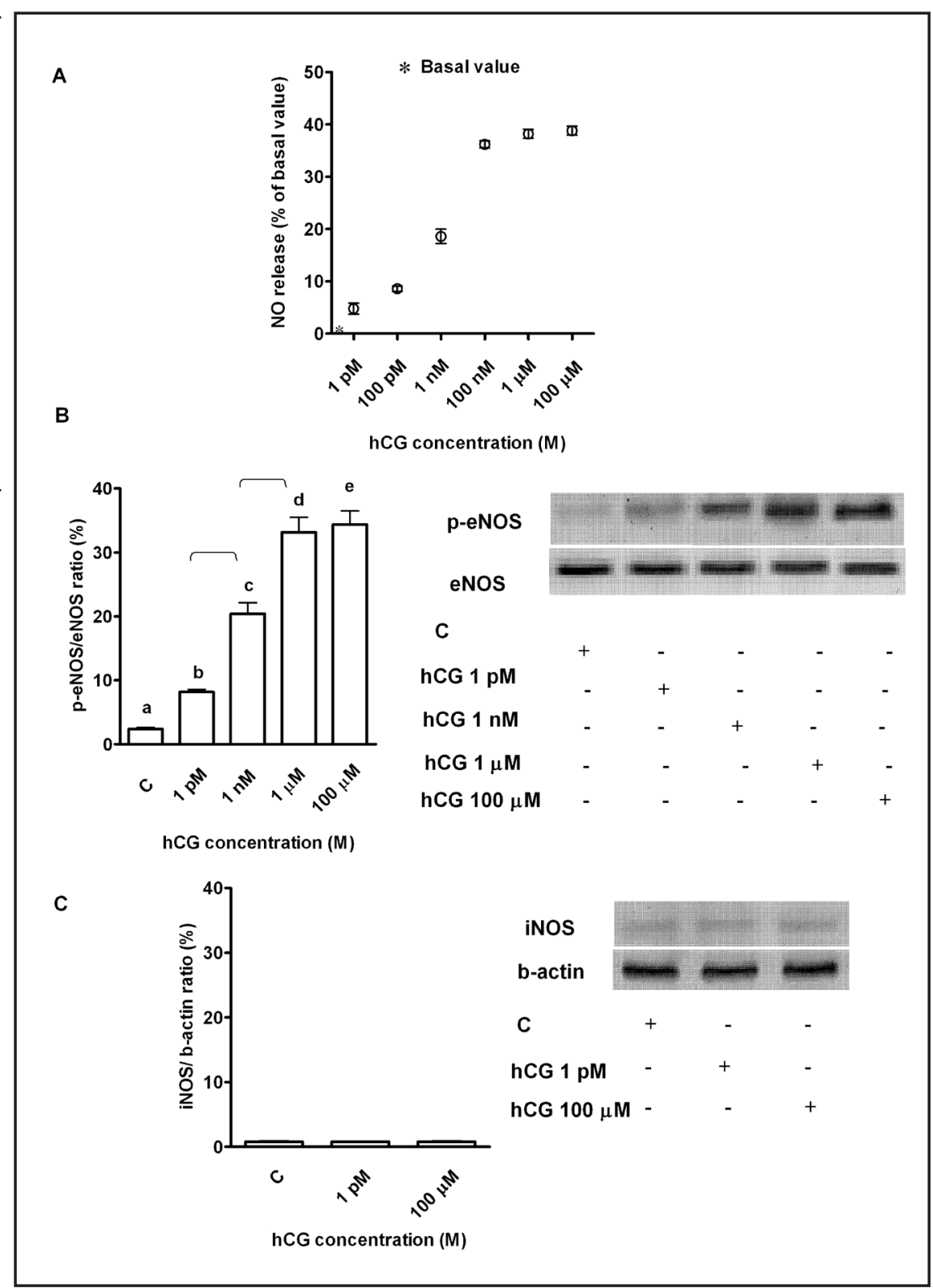

absence of hCG. Moreover, these effects were accompanied by increased activation of ERK1/2 and Akt (Fig. 8).

\section{Discussion}

The present results have shown that hCG can exert protection in human vascular vein endothelial cells against oxidative stress through the modulation of eNOS and iNOS, apoptosis inhibition and the keeping of mitochondrial function.

Pregnancy can be considered as a state of oxidative stress [18] arising from the increased metabolic activity in placental mitochondria and reduced scavenging power of antioxidants. However, in certain pathological pregnancies a heightened level of oxidative stress is encountered. This increased oxidative stress could affect placental function $[19,20]$ not only as a consequence of hypo-perfusion but also by enhanced apoptosis [21].

This is the first study showing that hCG can counteract peroxidative injuries in HUVEC by inhibition of apoptosis, the prevention of GSH reduction and the activation of 
Fig. 5. Effects of hCG on eNOS (A) and iNOS (B) activation in HUVEC under peroxidative conditions. hCG was administrated at $1 \mathrm{pM}, 1$ $\mathrm{nM}$, and $100 \mu \mathrm{m}$ for $60 \mathrm{~min}$ before $60 \min \mathrm{H}_{2} \mathrm{O}_{2}(200 \mu \mathrm{M})$. Densitometric analysis and an example of Western Blot taken from 5 different experiments are shown. For densitometric analysis p-eNOS was compared with eNOS, while iNOS was compared with b actin. b, c, d, e $P<0.05$ vs a; d, e $P<0.05$ vs b; e $P<0.05$ vs c. Square bracket indicates significance between the groups $(\mathrm{P}<0.05)$.
A
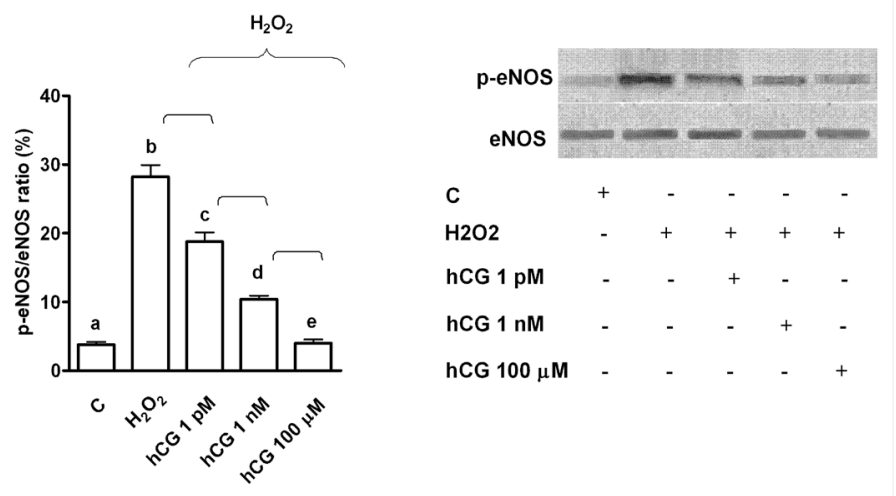

B

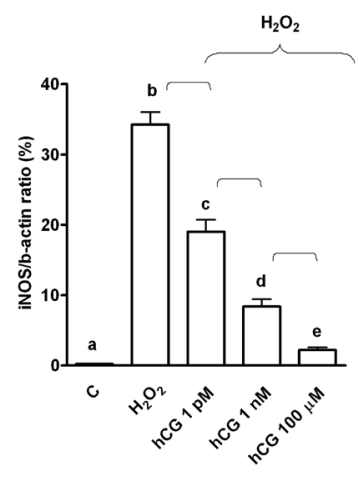

cell survival signalling. Hence, pre-treatment of cells with hCG at concentrations similar to those previously used in PAE and corresponding to plasma levels which can be achieved during pregnancy $[2,3]$, dose-dependently reduced cell death caused by hydrogen peroxide and prevented antioxidant system consumption. In particular, the activity of living cells observed by using $1 \mathrm{pM}$ hCG amounted to about $75 \%$ of control values of $100 \%$ and GSH content amounted to about $57 \%$ of control values. At $1 \mathrm{nM}$ hCG concentration, the activity of living cells had nearly returned to control values, whereas GSH content was slightly lower. At concentration higher than $1 \mu \mathrm{M}$, which most frequently can be observed during pregnancy, both the activity of living cells and GSH content were higher than basal values. These responses were accompanied by inhibiting effects on apoptotic markers and increased activation of members of the so-called reperfusion injury salvage kinases pathway [16, 22]. It is of interest to note that findings about apoptosis inhibition are in agreement with those obtained in human endometrial stromal cells, where hCG was able to inhibit the expression of the proapoptotic Bax protein and to up-regulate antiapoptotic Bcl-2 [10].

Taken together those observations would suggest that hCG might improve the uterine environment upon implantation by suppressing apoptotic responses in the maternal decidua and vasculature under oxidative stress. In this way hCG could counteract peroxidative conditions associated with endothelial dysfunction, which has been considered as a central patho-physiological event in the development of pre-eclamptic state [19].

Previous studies have demonstrated that NO can affect cellular decisions of life and death by either turning on or shutting off apoptotic pathways, suggesting that NO can function differently depending on the dose and duration of exposure [23]. Regarding this issue it is notable that while NO produced in low concentration, as in the case of eNOS activation, would act as a messenger and cytoprotective factor via direct interactions with transition 
Fig. 6. Effects of hCG on p-Bax (A) and Cytochrome $\mathrm{C}$ (B) in HUVEC treated with hydrogen peroxide. hCG was administrated at 1 $\mathrm{pM}, 1 \mathrm{nM}$, and 100 $\mu \mathrm{m}$ for $60 \mathrm{~min}$ before $60 \mathrm{~min} \mathrm{H}_{2} \mathrm{O}_{2}$ $(200 \mu \mathrm{M})$. Densitometric analysis and an example of Western Blot taken from 5 different experiments are shown. For densitometric analysis p-Bax was compared with Bax, while Cytochrome C was compared with b actin. b, c, d, e $P<0.05$ vs a; d, e $P<0.05$ vs b; e $P<0.05$ vs c. Square bracket indicates significance between the groups $(\mathrm{P}<0.05)$.

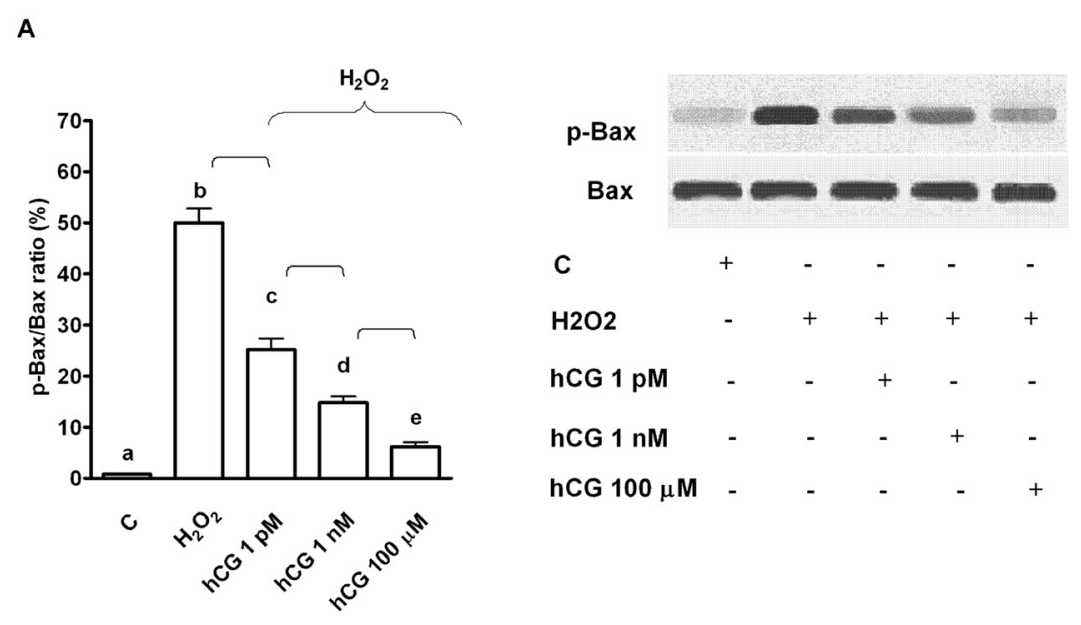

B



metals and other free radicals [23] it could increase reactive nitrose species formation and cause cellular death when over-secreted [24].

It is notable that in HUVEC hCG increased NO release in physiological conditions in a dose-dependent way, as was observed in PAE [2]. Those effects were accompanied by the activation of the only endothelial NOS isoform, which could account for the small amount of NO release found in that condition.

Different results were observed in cells treated with hydrogen peroxide. As previously found $[25,26]$, in HUVEC that were subjected to peroxidation an increase of both eNOS and iNOS was observed. Both NOS isoforms could be involved in increased NO release found in HUVEC during peroxidation. Hence, it is widely accepted that NO production higher than 2 $\mu \mathrm{Mol} / \mathrm{s}$, such as that found in HUVEC subjected to hydrogen peroxide, should be related to iNOS activation being NO release caused by eNOS in the range of nMol/s $[17,24]$. It is notable in HUVEC that were subjected to peroxidation and pre-treatment with hCG, NO production was lower than $1 \mu \mathrm{Mol} / \mathrm{s}$. Secondly, although eNOS itself could take place in increased NO release caused by hydrogen peroxide, at high extent peroxidation it could change its function. In respect of this issue it is worth noting that eNOS has recently been reported to be a redox "hub", being regulated by and contributing to the regulation of intracellular 
Fig. 7. Effects of hCG on cleaved Caspase $3(\mathrm{~A})$ and cleaved Caspase 9 (B) in HUVEC treated with hydrogen peroxide. hCG was administrated at $1 \mathrm{pM}, 1 \mathrm{nM}$, and 100 $\mu \mathrm{m}$ for $60 \mathrm{~min}$ before $60 \mathrm{~min}$ $\mathrm{H}_{2} \mathrm{O}_{2}(200 \mu \mathrm{M})$. Densitometric analysis and an example of Western Blot taken from 5 different experiments are shown. For densitometric analysis cleaved Caspase 3 and Caspase 9 were compared with b-actin and Caspase 9 . b, c, d, e $P<0.05$ vs a; d, e $P<0.05$ vs b; e $P<0.05$ vs c. Square bracket indicates significance between the groups $(\mathrm{P}<0.05)$.



redox homeostasis through mutually interacting tetrahydrobiopterin- and GSH-dependent pathways. Changes of GSH have been reported to cause eNOS uncoupling, which would cause the shift of the enzyme from NO to superoxide production [27]. This could, in turn, increase iNOS activation and strengthen NO release.

It could be hypothesized that in non-peroxidative condition hCG would activate eNOS, which in turn could increase NO release without exceeding physiological levels. Under peroxidation, eNOS activity, which would be increased by oxidative stress, could be impaired by concomitant uncoupling caused by GSH reduction. As a consequence, eNOS would augment the production of superoxide, which would potentiate the entire process by also increasing iNOS activity. Thus, hCG by restoring GSH levels could be useful for modulation of eNOS and iNOS function.

Anyway, although we could not precisely define the amount of NO caused by various NOS subtype, we can confirm the role of hCG in mediating protection against oxidative stress by the reduction of NO release, as previously reported [22]. This hypothesis has been confirmed by experiments performed with L-NAME, which also abolished NO release caused by hydrogen peroxide and caused an increase of the effects of hCG on cell survival and mitochondrial function.

Our findings are also of particular relevance when considering the different roles played by various NOS isoforms and related NO release in ovarian physiology and pregnancy $[28,29]$. While NO produced in low concentration would act as cytoprotective factor [30], NO overproduction could interfere with mitochondrial respiration and result in significant 
Fig. 8. Effects of hCG on p-Akt (A) and p-ERK1/2 (B) in HUVEC treated with hydrogen peroxide. hCG was administrated at $1 \mathrm{pM}, 1 \mathrm{nM}$, and 100 $\mu \mathrm{m}$ for $60 \mathrm{~min}$ before 60 $\min \mathrm{H}_{2} \mathrm{O}_{2}(200 \mu M)$. Densitometric analysis and an example of Western Blot taken from 5 different experiments are shown. For densitometric analysis p-Akt and p-ERK1/2 were compared with Akt and ERK1/2. b, c, d, e $P<0.05$ vs a; $d$, e $P<0.05$ vs b; e $P<0.05$ vs c. Square bracket indicates significance between the groups $(\mathrm{P}<0.05)$.

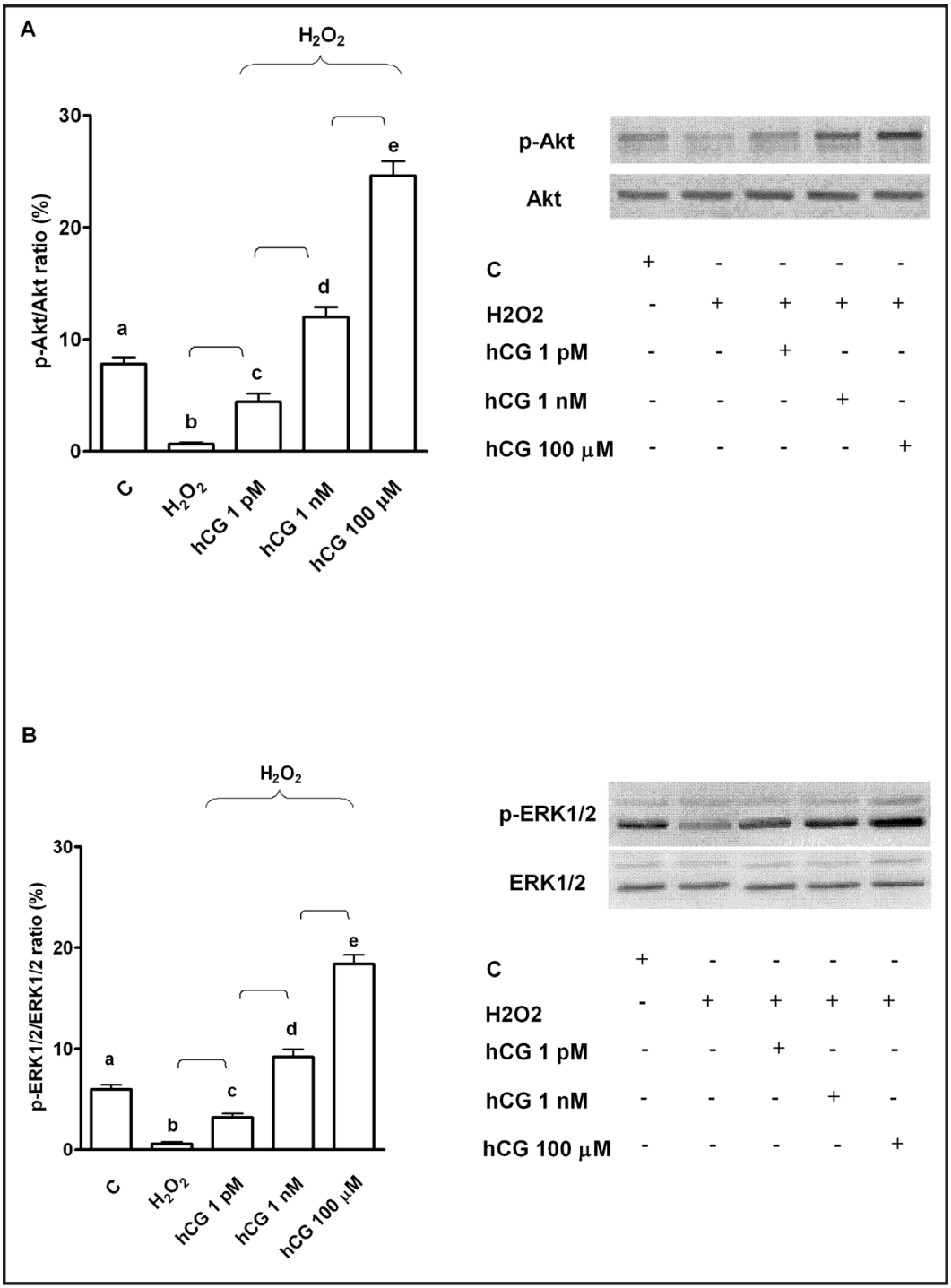

damage to cellular components and cellular death [31]. Also in ovaries, although follicular fluid NO derivatives are most likely to be necessary for oocyte activation at fertilization when produced within physiological limits, at higher doses they can have detrimental consequences on embryo quality, implantation and pregnancy rate [32].

The results obtained in this study about mitochondrial membrane potential and MPTP opening are of particular relevance and could be involved in the mechanism of protection exerted by hCG against peroxidation. Hence, the collapse of the mitochondrial membrane potential induced by MPTP opening could favour the release of Cytochrome c and downstream activation of effector caspases [33]. It is also notable that in endothelial cells from the umbilical artery of pre-eclamptic patients mitochondria have been found to be impaired [34, 35].

In the present study, pre-treatment of HUVEC with hCG prevented the collapse of mitochondrial membrane potential and MPTP opening caused by hydrogen peroxide. Furthermore, those effects were increased in cells pre-treated with L-NAME and counteracted by $5 \mathrm{HD}$. These findings not only confirmed the above arguments about the role of NO in protective effects elicited by hCG but also highlighted, for the first time, the involvement of mitoK $_{\text {ATP }}$ channels.

Taken together the results obtained in this study could have clinical implication in respect of the pathophysiology of pregnancy-related disorders and of the role of hCG. Hence, 


\section{Cellular Physiology Cell Physiol Biochem 2015;36:2108-2120

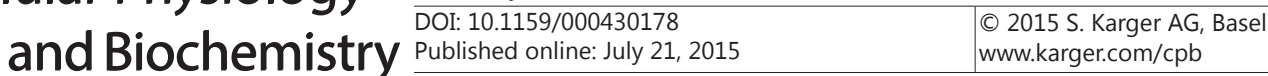 \\ Surico et al.: Antioxidant Effects of hCG in Endothelial Cells}

women with pre-eclampsia have been found to exhibit higher serum hCG and hydrogen peroxide than normotensive pregnant women at term [36]. Both in vivo and in vitro findings have shown that $\mathrm{H}_{2} \mathrm{O}_{2}$ can trigger placental hormone synthesis. Thus, overexpression of hCG could balance the detrimental effects of peroxidation on endothelial function [37], by inhibition of apoptosis and helping cell survival and mitochondria function. In particular, the antioxidant effects of hCG could be attributed to the combination of GSH content modulation and inhibition of mitochondrial membrane potential collapse and MPTP opening.

\section{Acknowledgments}

We thank the Azienda Ospedaliera Maggiore della Carita` di Novara for its help.

\section{Disclosure Statement}

None.

\section{References}

1 Lopata A, Oliva PG, Stanton DM, Robertson DM: Analysis of chorionic gonadotrophin secreted by cultured human blastocysts. Mol Hum Reprod 1997;3:517-521.

2 Grossini E, Surico D, Mary DA, Molinari C, Surico N, Vacca G: In anesthetized pigs human chorionic gonadotropin increases myocardial perfusion and function through a $\beta$-adrenergic-related pathway and nitric oxide. J Appl Physiol 2013;15:422-435.

3 Hermsteiner M, Zoltan DR, Doetsch J, Rascher W, Kuenzel W: Human chorionic gonadotropin dilates uterine and mesenteric resistance arteries in pregnant and nonpregnant rats. Pflugers Arch 1999;439:186194.

4 Roberts JM, Lain KY: Recent insights into the pathogenesis of preeclampsia. Placenta 2002;23: 359-372.

5 Roberts JM, Cooper DW: Pathogenesis and genetics of preeclampsia. Lancet 2001;357:53-56.

6 Lyall F, Myatt L: The role of the placenta in preeclampsia-a workshop report. Placenta 2002; 23:S142S145.

7 Granger JP, Alexander BT, Llinas MT, Bennett WA, Khalil RA: Pathophysiology of preeclampsia: linking placental ischemia/hypoxia with microvascular dysfunction. Microcirculation 2002;9:147-160.

8 Hubel CA: Oxidative stress in the pathogenesis of preeclampsia. Proc Soc Exp Biol Med 1999; 222:222-235.

9 Vaughan JE, Walsh SW: Oxidative stress reproduces placental abnormalities of preeclampsia. Hypertens Pregnancy 2002;21:205-223.

10 Kajihara T, Uchino S, Suzuki M, Itakura A, Brosens JJ, Ishihara O: Human chorionic gonadotropin confers resistance to oxidative stress-induced apoptosis in decidualizing human endometrial stromal cells. Fertil Steril 2011;95:1302-1307.

11 Dantzer V, Leach L, Leiser R: Angiogenesis and placental vasculature-A workshop report. Placenta 2000;21:S69-S70.

12 Zygmunt M, Hahn D, Munstedt K, Bischof P, Lang U: Invasion of cytotrophoblastic JEG-3 cells is stimulated by hCG in vitro. Placenta 1998;19:587-593.

13 Jaffe EA, Nachman RL, Becker CG, Minick CR: Culture of human endothelial cells derived from umbilical veins. Identification by morphologic and immunologic criteria. J Clin Invest 1973; 52:2745-2756.

14 Grossini E, Molinari C, Caimmi PP, Uberti F, Vacca G: Levosimendan induces NO production through p38 MAPK, ERK and Akt in porcine coronary endothelial cells: role for mitochondrial KATP channel. Br J Pharmacol 2009;156:250-261.

15 Grossini E, Caimmi P, Molinari C, Uberti F, Mary D, Vacca G: CCK receptors-related signaling involved in nitric oxide production caused by gastrin 17 in porcine coronary endothelial cells. Mol Cell Endocrinol 2012;350:20-30. 


\section{Cellular Physiology Cell Physiol Biochem 2015;36:2108-2120 \begin{tabular}{l|l|l}
\hline DOI: 10.1159/000430178 & C 2015 S. Karger AG, Basel
\end{tabular} Published online: July 21, $2015 \quad$ www.karger.com/cpb \\ Surico et al.: Antioxidant Effects of hCG in Endothelial Cells}

16 Grossini E, Gramaglia C, Farruggio S, Bellofatto K, Anchisi C, Mary D, Vacca G, Zeppegno P: Asenapine increases nitric oxide release and protects porcine coronary artery endothelial cells against peroxidation. Vascul Pharmacol 2014;60:127-141.

17 Uberti F, Caimmi PP, Molinari C, Mary D, Vacca G, Grossini E: Levosimendan modulates programmed forms of cell death through K(ATP) channels and nitric oxide. J Cardiovasc Pharmacol 2011;57:246-258.

18 Wisdom SJ, R. Wilson R, McKillop JH, Walker JJ: Antioxidant systems in normal pregnancy and in pregnancy-induced hypertension. Am J Obstet Gynecol 1991;165:1701-1704.

19 Llurba E, Gratacós E, Martín-Gallán P, Cabero L, Dominguez L: A comprehensive study of oxidative stress and antioxidant status in preeclampsia and normal pregnancy Free Radic Biol Med 2004;37:557-570.

20 Myatt L, Cui XL: Oxidative stress in the placenta Histochem. Cell Biol 2004;122:369-382.

21 Shaker OG, Sadik NA: Pathogenesis of preeclampsia: Implications of apoptotic markers and oxidative stress. Hum Exp Toxicol 2013;32:1170-1178.

22 Cappellano G, Uberti F, Caimmi PP, Pietronave S, Mary DA, Dianzani C, Micalizzi E, Melensi M, Boldorini R, Nicosia G, Crosio E, Chiocchetti A, Aina F, Prat M, Dianzani U, Vacca G, Ariatti C, Grossini E: Different expression and function of the endocannabinoid system in human epicardial adipose tissue in relation to heart disease. Can J Cardiol 2013;29:499-509.

23 Liaudet L, Soriano FG, Szabó C: Biology of nitric oxide signaling. Crit Care Med 2000;28: N37-52.

24 Razavi HM, Hamilton JA, Feng Q: Modulation of apoptosis by nitric oxide: implications in myocardial ischemia and heart failure. Pharmacol Ther 2005;106:147-162.

25 Thomas SR, Chen K, Keaney JF Jr: Hydrogen peroxide activates endothelial nitric-oxide synthase through coordinated phosphorylation and dephosphorylation via a phosphoinositide 3-kinase-dependent signaling pathway. J Biol Chem 2002;277:6017-6024.

26 Zadeh MS, Kolb JP, Geromin D, D'Anna R, Boulmerka A, Marconi A, Dugas B, Marsac C, D'Alessio P: Regulation of ICAM-1/CD54 expression on human endothelial cells by hydrogen peroxide involves inducible NO synthase. J Leukoc Biol 2000;67:327-334.

27 Crabtree MJ, Brixey R, Batchelor H, Hale AB, Channon KM: Integrated redox sensor and effector functions for tetrahydrobiopterin- and glutathionylation-dependent endothelial nitric-oxide synthase uncoupling. J Biol Chem 2013;288:561-569.

28 Anteby EY, Hurwitz A, Korach O, Revel A, Simon A, Finci-Yeheskel Z, Mayer M, Laufer N: Human follicular nitric oxide pathway: relationship to follicular size, oestradiol concentrations and ovarian blood flow. Hum Reprod 1996;11:1947-1951.

29 Ben-Shlomo I, Adashi EY, Paync DW: The morphogenic/cytotoxic and prostaglandin stimulating activities of interleukin-1b in the rat ovary are NO independent. J Clin Invest 1994;49: 1463-1469.

30 Moncada S, Palmer RMJ, Higgs EA: Nitric oxide: physiology, pathophysiology, and pharmacology. Pharmacol Rev 1991;43:109-142.

31 Anggard E: Nitric oxide: mediator, murderer, and medicine. Lancet 1994;343:1199-1206.

32 Battaglia C, Regnani G, Marsella T, Facchinetti F, Volpe A, Venturoli S, Flamigni C: Adjuvant L-arginine treatment in controlled ovarian hyperstimulation: a double-blind, randomized study. Hum Reprod 2002;17:659-665.

33 Green DR, Reed JC: Mitochondria and apoptosis. Science 1998;281:1309-1312.

34 Kanter M, Gurbuz H, Okman TK: Endothelial nitric oxide synthase immunreactivity and the ultrastructure of endothelial cells of umbilical artery in normal and preeclamptic pregnancies. Clin Exp Hypertens 2010;32:458-463.

35 Illsinger S, Janzen N, Sander S, Schmidt KH, Bednarczyk J, Mallunat L, Bode J, Hagebölling F, Hoy L, Lücke T, Hass R, Das AM: Preeclampsia and HELLP syndrome: impaired mitochondrial function in umbilical endothelial cells. Reprod Sci 2010;17:219-226.

36 Kharfi A, Giguère Y, De Grandpré P, Moutquin JM, Forest JC: Human chorionic gonadotropin (hCG) may be a marker of systemic oxidative stress in normotensive and preeclamptic term pregnancies. Clin Biochem 2005;38:717-721.

37 Kharfi A, Leblanc S, Ouellet A, Moutquin JM: Dual action of H2O2 on placental hCG secretion: implications for oxidative stress in preeclampsia. Clin Biochem 2007;40:94-97. 